\title{
ALGORITHM FOR QUANTIFYING THE PARTICLE SIZE DISTRIBUTION OF NON-METALLIC INCLUSIONS FORMATION IN STEEL PRODUCTION
}

\author{
Marija Mihailović ${ }^{1 *}$, Karlo Raić2 \\ ${ }^{1}$ University of Belgrade - Institute of Chemistry, Technology and Metallurgy - National \\ Institute of the Republic of Serbia, Njegoševa 12, 11000 Belgrade, Serbia \\ ${ }^{2}$ University of Belgrade, Faculty of Technology and Metallurgy, Karnegijeva 4, \\ 11000 Belgrade, Serbia
}

Received 07.12.2021

Accepted 24.12.2021

\begin{abstract}
When the quantitative characterization of non-metallic inclusions in steel is done and the effect of limiting factors is assessed, and based on that the possibility of reconstruction of the total content of non-metallic inclusions in steel is estimated, further considerations can be directed towards predicting the model of the size distribution curve. The aim of this work is to establish relations based on which it will be possible to quantify the content of non-metallic inclusions in extra-pure steels, when metallographic control is difficult or even impossible by routine procedures.
\end{abstract}

Keywords: deoxidation; nonmetallic inclusions; clean steel; log-normal distribution.

\section{Introduction}

Non-metallic inclusions are deoxidation products in the steelmaking process. Their final number and shape in the steel structure is the result of three spontaneous processes:

-nucleation of stable nuclei, formed from oxygen dissolved in steel and added deoxidizer;

-growth of inclusions by various mechanisms, the most effective is an enlargement of small inclusions by collisions;

-floating non-metallic inclusions and their transition to slag or adhering to the refractory lining.

Process parameters influencing the final number and size of inclusions after steel hardening are the initial oxygen content in steel, before deoxidation, and the available

${ }^{*}$ Corresponding author: Marija Mihailović, marija.mihailovic@ihtm.bg.ac.rs 
time from the beginning of deoxidation to steel solidification. The time is especially important when strong deoxidizing agents are used, after the addition of which very little dissolved oxygen remains in the liquid steel [1,2].

Chemical analysis of oxygen, which upon addition of deoxidizers causes the formation of non-metallic oxide inclusions, is taken as a measure of bulk inclusion content in steel and a criterion of steel cleanness. Since oxygen solubility in the metal matrix is very low, the bulk oxygen concentration in steel can be calculated based on the oxide inclusions content. The difference between the oxygen content obtained by chemical analysis and the calculated one, indicates that it is not possible to determine all the parameters by routine examination of steel $[2,3]$.

Major factors which affect the inclusions distribution curve shape are: the concentration of oxygen in the melt at the time of outflow $\Sigma \mathrm{O}$, and in connection with that the amount of residual oxygen after inclusions floating [O], as well as the time $(\tau)$ available to inclusions to grow by collisions, and then to float before the steel solidifies [2, 4-7].

Normal (Gaussian) distribution is a continuous probability distribution curve, which is symmetric on both sides, a so-called bell curve. It is a very important distribution of a random variable, which could be the case with the size of non-metallic inclusions size in steel. Some complicated distribution curves can be approximated and transformed into the normal distribution using mathematical theorems [2, 3]. Besides, numerous variables that can be used for the verification of statistical tests are distributed according to normal distribution law. Since the mean value distribution of non-metallic inclusions volume fractions $(X)$ does not obey the normal law of distribution, the measurement results are suggested to be grouped into sets by size, where each set should encompass 30-100 adjacent view fields [5]. The standard method to test the data distribution normality is to calculate four mean values momentum $\left(U_{1}, U_{2} U_{3}, U_{4}\right)$, based on the mean values of each set $\left(X_{1}, X_{2}, \ldots, X_{n}\right)$. To calculate them, zero momentum $\left(A_{1}, A_{2}, A_{3}, A_{4}\right)$ must be determined:

$$
\begin{aligned}
& A_{1}=\sum\left(X_{1}+X_{2}+X_{3}+\cdots+X_{n}\right) \\
& A_{2}=\sum\left(X_{1}^{2}+X_{2}^{2}+X_{3}^{2}+\cdots+X_{n}^{2}\right) \\
& A_{3}=\sum\left(X_{1}^{3}+X_{2}^{3}+X_{3}^{3}+\cdots+X_{n}^{3}\right) \\
& A_{4}=\sum\left(X_{1}^{4}+X_{2}^{4}+X_{3}^{4}+\cdots+X_{n}^{4}\right)
\end{aligned}
$$

The arithmetic mean value of each measurement set is determined by the equation:

$V_{i}=A_{i} / n$

where $n$ is the number of the measured values. 
These mean values of the measuring sets are used to determine the moments of the mean values (U) of the third and fourth order, used to calculate the coefficients of asymmetry and excess (flattening). The moments of the second, third and fourth order are:

$$
\begin{aligned}
& U_{2}=V_{2}-V_{l}^{2} \\
& U_{3}=V_{3}-3 V_{l} V_{2}+2 V_{l}^{3} \\
& U_{4}=V_{4}-4 V_{l} V_{3}+6 V_{l}^{2} V_{2}-3 V_{l}^{4},
\end{aligned}
$$

so the coefficient of asymmetry $\beta_{1}$ and the coefficient of excess $\beta_{2}$ are calculated according to the patterns:

$$
\beta_{1}=\frac{U_{3} \cdot\left|U_{3}\right|}{\left(U_{2}\right)^{3}} ; \beta_{2}=\frac{U_{4}}{\left(U_{2}\right)^{2}}
$$

The shape of the distribution curve is commonly described by the coefficients of asymmetry and excess ( $\beta_{1}$ and $\beta_{2}$, calculated according to equation 9 ), so they can be related to the parameters influencing the formation of the distribution curve shape. These parameters are determined by the size range and the number of non-metallic inclusions contained in the steel.

\section{Experimental Work}

Deoxidation of steel occurs when deoxidizing agents with high affinity for oxygen ( $\mathrm{Mn}, \mathrm{Si}, \mathrm{Al} \mathrm{Ca}$, etc.) are added to a liquid steel. If silicon is used as a deoxidizing agent, killed steel is obtained, and if aluminum is used, double killed steel is obtained. Both deoxidizers were used in this work, with $\mathrm{Al}$ being added in pure form. After deoxidation, the amount of $\mathrm{Al}$ in the steel is shown in Table 1 . The oxide non-metallic inclusions in continuous cast low carbon aluminum killed deep drawing steel, produced on a vertical continuous caster, were examined. The chemical composition of the steel is given in Table 1 and the industrial casting conditions are shown in Table 2.

Table 1. Chemical composition of the steel in mass percent (\%).

\begin{tabular}{llllllll}
\hline $\mathrm{C}$ & $\mathrm{Si}$ & $\mathrm{Mn}$ & $\mathrm{P}$ & $\mathrm{S}$ & $\mathrm{Al}$ & $\mathrm{Cu}$ & {$[\mathrm{O}]$} \\
\hline & & & & & & & \\
$0.07-$ & $0.03-$ & $0.37-$ & $0.02-$ & $0.026-$ & $0.06-$ & & \\
0.06 & 0.02 & 0.35 & 0.018 & 0.025 & 0.043 & 0.0054
\end{tabular}


As-cast condition is chosen because of larger inclusion size, and in that case their predominantly centrally symmetrical shape. Thus, the interfering effect of inclusion size reduction and disintegrated aluminate inclusions clustering during hot and cold working is avoided. Inclusions are visually identified and counted on the polished unetched surface. The number and size of all inclusions are recorded and measured using the standard planimetric method. With the aim to ensure unbiased counting and size determination, as well as better accuracy and later results checking, the measurements were carried on the microphotographs, taken from the serial production of the local steel plant. The detailed analysis of these, very extensive data is presented in the thesis [4] as well as paper [9].

A sample is taken from a slab of $200 \times 1400 \mathrm{~mm}$ cross section, encompassing its half thickness. The non-metallic inclusions are examined on the surface oriented perpendicularly to the casting direction, sizing $3 \times 3 \mathrm{~mm}$, with center distanced $63.5 \mathrm{~mm}$ from the slab surface.

For final polishing both $1 \mu \mathrm{m}$ and $1 / 4 \mu \mathrm{m}$ diamond polish pastes are used. The same sample surface was examined for each polish variations at x 400 and $\mathrm{x} 1024$ magnification. At the magnification of $\mathrm{x} 400$, the whole sample surface of $9 \mathrm{~mm}^{2}$ was examined, paying attention not to overlap adjacent view fields. The sum of 320 view fields was observed. At the magnification of x1024 the equidistantly distributed view fields over the sample surface were examined and the sum of 100 view fields amounted to $0.4736 \mathrm{~mm}^{2}$.

Table 2. Industrial continuous casting conditions.

\begin{tabular}{llllll}
\hline Lot & $\begin{array}{l}\text { Slab } \\
\text { thickness } \\
(\mathrm{mm})\end{array}$ & $\begin{array}{l}\text { Cast } \\
\text { speed } \\
(\mathrm{m} / \mathrm{min})\end{array}$ & $\begin{array}{l}\text { Oscillation } \\
\text { number } \\
(\mathrm{o} / \mathrm{min})\end{array}$ & $\begin{array}{l}\text { Working rollers } \\
\text { pressure }(\mathrm{MPa})\end{array}$ & $\begin{array}{l}\text { Cast } \\
\text { temperature } \\
\left({ }^{\circ} \mathrm{C}\right)\end{array}$ \\
\hline 4 & $1040 \times 200$ & 0,55 & 50 & 1,10 & 1570 \\
11 & $1040 \times 200$ & 0,5 & 75 & 1,12 & 1535 \\
\hline
\end{tabular}

\section{Phenomenological basis of the algorithm}

Phenomenologically the amount of non-metallic inclusions, expressed by their number, and the size, stated as a function of time, for a given process and oxygen content, is illustrated by Figure 1 [6]. 


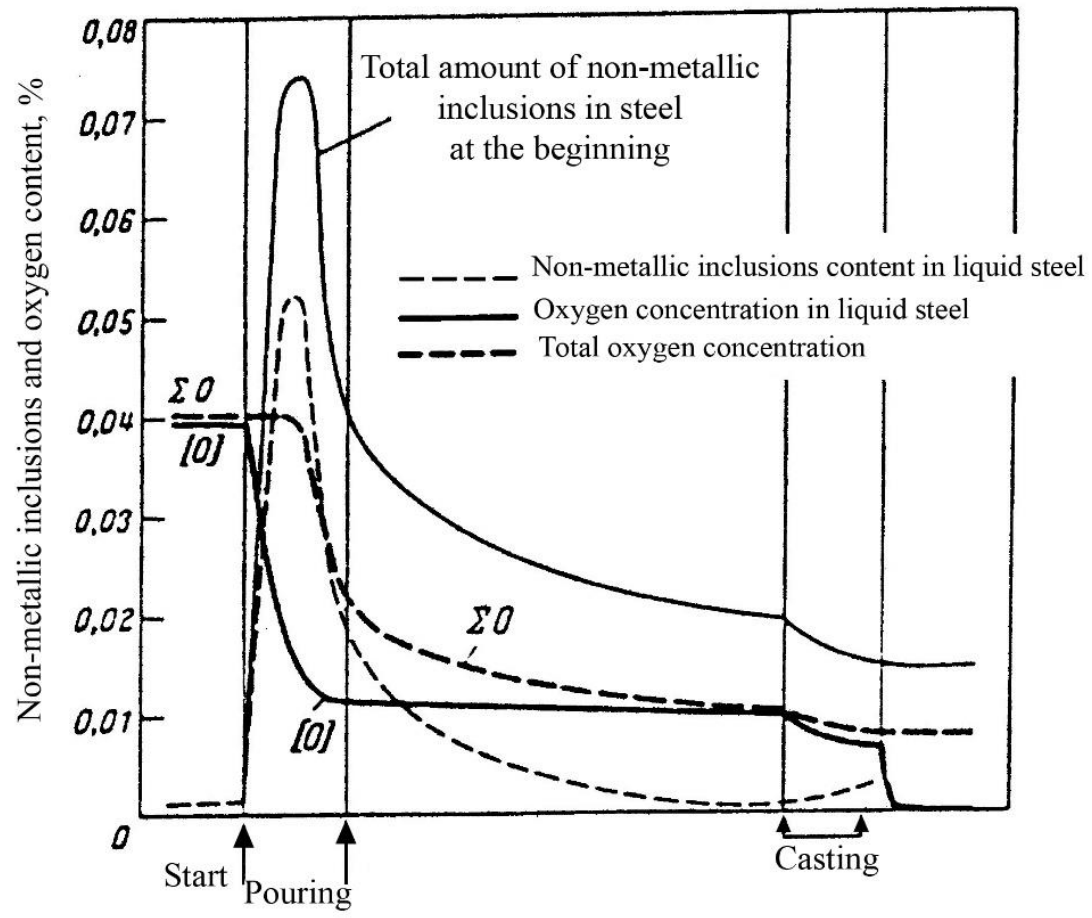

Fig. 1. Distribution of oxide non-metallic inclusion during primary steel production and casting [6].

The diagram in Figure 1, through the content of total and dissolved oxygen in the steel, illustrate the change in the amount of deoxidation products as a function of time, for a given oxygen content, after refining and deoxidation process. It can be seen that the amount of non-metallic inclusions in steel, which is implicitly correlated with both processes, growth by collisions and floating, depends on both the time and the type of deoxidizing agent. It also can be seen that time is not linearly correlated with the growth and floating of deoxidation products, but in periods of turbulent hydrodynamic conditions during intensive mixing, i.e. during casting, or in ladle and casting, both processes are significantly intensified. The diagram clearly indicates that clean steel, in terms of oxide non-metallic inclusions can be obtained as a result of extended duration, i.e., increased agitation intensity, primarily during ladle processing, and that the initial oxygen content is not a decisive factor.

The analysis of influencing factors to the formation of the shape of the distribution must be related to the coefficients that describe the shape of the curve. The asymmetry coefficient $\left(\beta_{l}\right)$ indicates the degree of distribution asymmetry, and a positive value indicates that the distribution is asymmetric to the right, which is the case here. The coefficient of excess $\left(\beta_{2}\right)$ speaks of the flattening or convexity of the distribution curve and is of little importance if not comparing distribution curves. The distribution with the highest coefficient of excess has the most pronounced peak $[2,7]$ 
Since both $\beta_{1}=f([\mathrm{O}], \tau)$ and $\beta_{2}=f([\mathrm{O}], \tau)$, are dependent on the amount of residual oxygen after inclusions floating [O], as well as the time $(\tau)$, the two boundary conditions should be set for further analysis. The first boundary condition when the oxygen concentration changes, and the time available for the inclusions to grow by collisions is constant. Such a situation is a reality when lot 4 and lot 11 are compared, as in this case. Oxygen content is lowered in lot 11 comparing to lot 4 , and time can be considered constant since their production regime is the same (see parameters from Table 2). Comparing the coefficients of excess for both lots, 4 and 11, Table 3, it can be concluded that the convexity of the curve decreases with decreasing oxygen content, for a constant time. Moreover, the minimum coefficient of excess in a lot with higher oxygen content is higher than the maximum coefficient of excess in a lot with a lower oxygen concentration. The asymmetry coefficients are generally higher for a lot with higher oxygen content.

The second boundary condition occurs in the case of a constant oxygen concentration, while the time available for the inclusions to grow by collisions varies. Such a situation exists for samples within one lot, going from A to D position, as Table 3 illustrates. Samples from position A are in the surface zone of the ingot, where the time for growth is shortest, while samples at position D inclusions had an additional 15-20 minutes for growth. According to Table 3, it is obvious that for the same oxygen content, the coefficient of excess increases with the increase of the time that the inclusions had at their disposal, Table 3 . The asymmetry coefficient within lot 4 decreases with increasing time, while for lot 11 it is constant.

Table 3. Overview of the coefficients describing the shape of the distribution curve.

\begin{tabular}{|c|c|c|c|c|c|c|}
\hline \multirow{2}{*}{ Lot } & \multirow{2}{*}{ Sample } & \multirow{2}{*}{$\begin{array}{l}\text { Number of } \\
\text { examined } \\
\text { fields }\end{array}$} & \multicolumn{2}{|c|}{$\begin{array}{l}\text { Asymmetry coefficient } \\
\qquad\left(\beta_{1}\right)\end{array}$} & \multicolumn{2}{|c|}{ Coefficient of excess $\left(\beta_{2}\right)$} \\
\hline & & & Exp. & Theoretical & Exp. & Theoretical \\
\hline & A & 253 & 2.87 & 0.07 & 8.32 & 2.60 \\
\hline 4 & B & 266 & 0.19 & 0.008 & 2.70 & 2.75 \\
\hline \multirow[t]{2}{*}[\mathrm{O}]{$=67 \mathrm{ppm}$} & $\mathrm{C}$ & 320 & 0.001 & 0.05 & 3.29 & 3.02 \\
\hline & $\mathrm{D}$ & 450 & 0.73 & 0.02 & 4.39 & 3.50 \\
\hline & A & 493 & 0.01 & 0.007 & 2.25 & 2.35 \\
\hline \multirow{2}{*}[\mathrm{O}]{$=54 \mathrm{ppm}$} & B & 368 & 0.4 & 0.007 & 2.45 & 2.50 \\
\hline & $\mathrm{C}$ & 320 & 0.04 & 0.007 & 6.87 & 2.50 \\
\hline
\end{tabular}




\section{Since}

$\mathrm{N}_{\Sigma^{\prime}}=f[\mathrm{O}], \mathrm{N}_{\Sigma}=f[\mathrm{O}, \tau]$ and $\mathrm{d}_{\mathrm{av}}=f[\mathrm{O}, \tau]$,

And: $\mathrm{N}_{\Sigma}{ }^{\prime}$ - total number of non-metallic inclusions that depend only on the oxygen content if the time required to float is not taken into account, $\mathrm{N}_{\square \square \square \square}$ total number of nonmetallic inclusions when floating is taken into account, and $\mathrm{d}_{\mathrm{av}}$ - mean diameter of inclusions, the conclusion is that certain relations can be established between these distribution parameters and the describing coefficients $\left(\beta_{1}\right.$ and $\left.\beta_{2}\right)$.

However, for further discussion, it is necessary to recall the meanings of median and mode. The median (Me) is the middle value of a distribution when a data set is ordered from smallest to greatest. The mode (Mo) is the most frequent number in a data set. Mode is a numerical characteristic of a random variable that corresponds to the maximum probability. In asymmetric distributions, in the case of positive asymmetry, the mean value is shifted to the right relative to mode. In contrast, in symmetric distributions mode overlaps with mean and median at the maximum of the distribution curve.

Thus, for two distribution curves with different values of coefficient of excess, if the mode has the same value, i.e. the asymmetry coefficient is the same for both observed curves - in our case it corresponds to the same diameter in both distributions - one can speak of a greater or lesser probability maximum for that diameter, that is a greater or lesser number of inclusions of that diameter.

Suppose the change of the asymmetry coefficient is taken into account. In that case, it is important to know that higher positive values mean greater asymmetry to the right, i.e. the maximum corresponding to mode is then shifted more to the left, towards a smaller diameter.

There are certain relationships between mean, mode, and median in very asymmetric distributions [7], but this does not indicate that the mean diameter corresponding to the distribution is distinctively smaller for the higher the asymmetry coefficient. It may indicate just the tendency of diameter change.

If the change in the asymmetry coefficient is taken into consideration, it is important to know that higher positive values mean more asymmetry to the right, i.e., the maximum corresponding to the mode is shifted more to the left, towards lower diameter values.

So, when the oxygen concentration is constant, and the time available for inclusions to grow by collisions is prolonged, then the coefficient of excess increases, i.e., the number of inclusions that have grown to a specific size increases. With time extension, the asymmetry coefficient has a smaller positive value, so a tendency to increase the mean diameter can be expected. However, for favorable conditions, floating can also prevail here. The curves in Figures $2 \mathrm{a}$ and $2 \mathrm{~b}$ illustrate this situation for $\square_{1}<\square_{2}<\square_{\mathrm{n}}$; Figure 2a schematically shows the evolution of the inclusions size distribution curve over time, when floating predominates over growth by collisions, while Figure $2 b$ shows a situation where growth by collisions predominates over floating. 


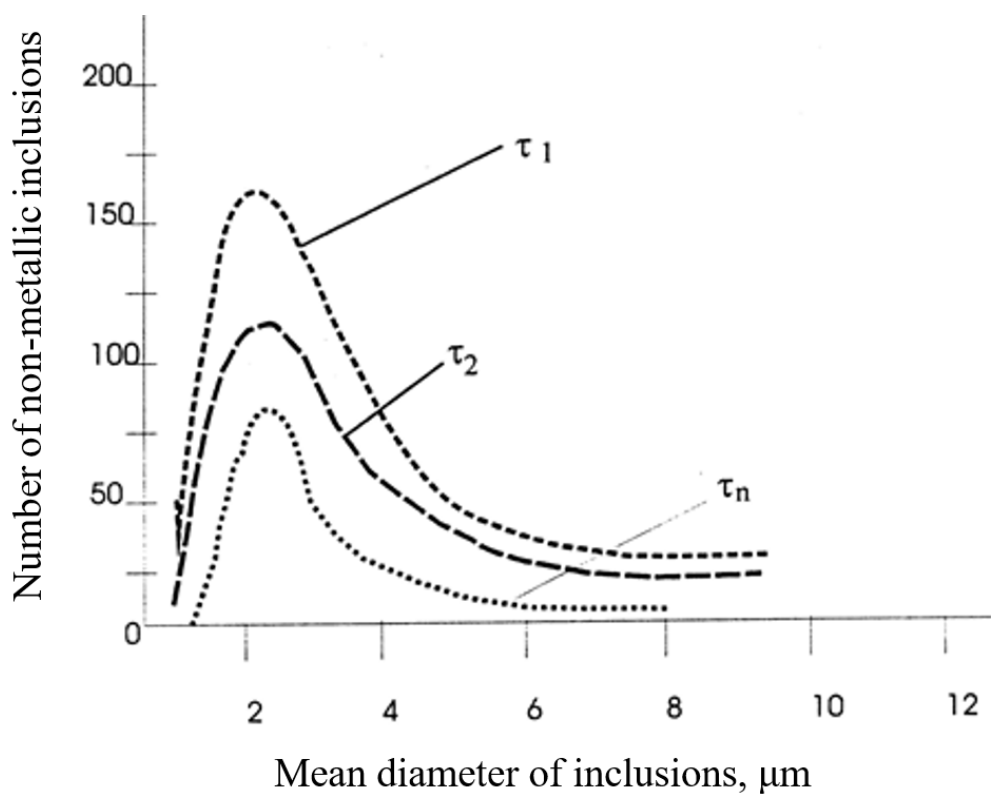

(a)

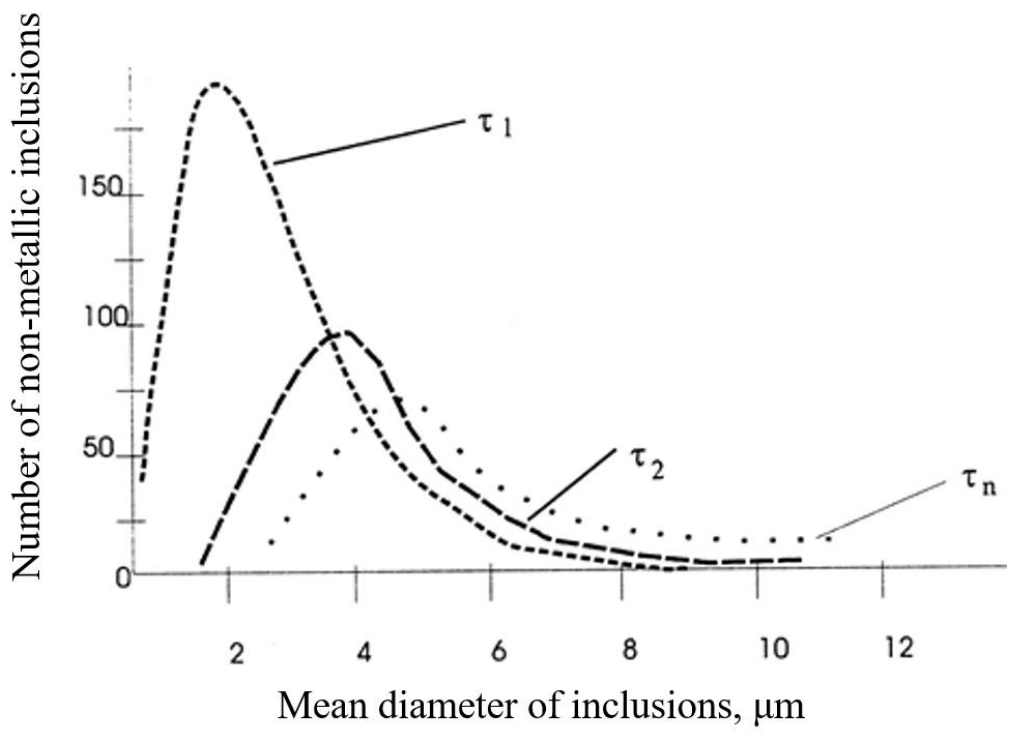

(b)

Fig. 2 a) Distribution curves of oxide non-metallic inclusions, when floating predominates over growth by collisions and b) Distribution curves of oxide non-metallic inclusions, when growth by collisions predominates over floating. 
When the time available for inclusions to grow by collisions is constant, and the oxygen concentration decreases (here: lot " 4 " with higher and lot " 11 " with lower oxygen content), then the value of the excess coefficient decreases, i.e., the number of inclusions that reached a certain size decreases too. As the oxygen concentration decreases, the number of formed nuclei is lower, and thus a probability is lower for the occurrence of the collisions during which the inclusions will enlarge. The asymmetry coefficient decreases less markedly with decreasing oxygen concentration, so the time to grow is more important than the oxygen content in respect of this coefficient.

This result coincides with the previous conclusion that the initial oxygen content is not a critical factor for obtaining pure steel in terms of non-metallic inclusions but that it is a prolonged and adequate hydrodynamic regime of steel ladle processing.

\section{The mathematical basis of the algorithm}

Based on the Equations (1-9), in the case of very clean steels, which are very difficult to examine by routine metallographic methods, the algorithm for possible distribution predicting can be evaluated. In the case of Al killed steel, non-metallic inclusions are $\mathrm{Al}_{2} \mathrm{O}_{3}$. The further calculation is as follows:

$$
[\% O]=N I(\%) \frac{\rho_{N I} \cdot 3 M(O)}{\rho_{\text {steel }} \cdot(2 M(A l)+3 M(O))}[\mathrm{ppm}]
$$

Non-metallic inclusions surface portion, $N I(\%)$ can be expressed as:

$$
N I=\left(A_{\text {theor }} / A_{\text {exp }}\right) \cdot 100(\%)
$$

where:

$\mathrm{A}_{\mathrm{exp}}$-examined surface area

$\mathrm{A}_{\text {theor }}$ - total surface with inclusions on the examined surface.

$\mathrm{A}_{\exp }=(a \cdot b) \cdot \mathrm{N}_{\text {fields }}=(205 \cdot 140) \cdot 100=2870000 \mu \mathrm{m}^{2}$

$a, b$-dimensions of a view field

$\mathrm{N}_{\text {polja }}$ - number of examined fields.

To be mutually comparable, all literature data on distributions, are normalized to 100 fields, so its principle was used here for the calculation, i.e., the number of fields is normalized to $100[2,4]$.

The total surface with inclusions on the examined surface may be simply calculated as

$\mathrm{A}_{\text {teor }}=\left(\mathrm{d}^{2} \cdot \pi / 4\right) \cdot N$, where: $N$ is the number of inclusions for each size class, and $d$ is the mean diameter of the inclusions of a given size class. So, the mean diameter of the inclusions can be expressed:

$$
d=\sqrt{\frac{4 \cdot[\% O] \cdot A_{\text {exp }}}{\pi n \cdot \text { const } \cdot 100}}
$$

For the aluminate type of non-metallic inclusions, the constant can be calculated based on atomic mass and density, and it is as follows: const $=0,233795$.

Based on the results of analyzed distributions, i.e., oxygen content and the calculated mean value of the number of inclusions by size classes, the average distribution 
curves can be obtained for, lot 4 and 11. Using Eq. 12 the diameter of non-metallic inclusions was calculated, which, based on the number of inclusions and oxygen content, corresponds to the average diameter of a certain size class.

Statistical analysis shows that the average distribution curve obeys the log-normal distribution law. The asymmetry coefficient of the average curve calculated for lot "4" is 0.0619 , and the excess coefficient is 2.65 . The asymmetry coefficient of the average curve calculated for lot "11" is 0.0417 , and the excess coefficient is 2.45 [8].

The average distribution should include the characteristic properties of the distribution of oxide non-metallic inclusions in aluminum killed, continuously cast steel. If it is assumed that the steel with 6ppm [O] is analyzed, then on the basis of the previously known percentage distribution of oxygen by classes, the distribution of [O] ppm by size classes can be obtained. Considering that the largest inclusion is in class I, assuming that there is only one (which is usually the case), the diameter of that inclusion can be calculated using Equation 12. Based on the step between the size classes, it becomes possible to calculate diameters in all other classes as well. The newly obtained distribution, according to the algorithm, for lot "4" is also log-normal with an excess coefficient of 2.36 and an asymmetry coefficient of 0.0535 . The excess coefficient of the newly obtained distribution in lot "11" is 2.16 , and the asymmetry coefficient is 0.0493 . All these coefficients ate summarized in Table 4.

Calculation on the quantity of oxygen they would represent, expressed in ppm, based on the newly obtained values of the inclusions diameter, gives $5.74 \mathrm{ppm}$, which completely satisfies the initial assumption about steel with $6 \mathrm{ppm}$ of oxygen.

Table 4. Asymmetry and excess coefficient: average and using algorithm calculated.

\begin{tabular}{lcc}
\hline $\begin{array}{l}\text { Non-metallic Inclusions } \\
\text { distribution }\end{array}$ & $\begin{array}{c}\text { Asymmetry coefficient } \\
\left(\beta_{1}\right)\end{array}$ & $\begin{array}{c}\text { Coefficient of excess } \\
\left(\beta_{2}\right)\end{array}$ \\
\hline $\begin{array}{l}\text { Average distribution "4" } \\
\text { Average distribution "11" }\end{array}$ & 0.0619 & 2.65 \\
$\begin{array}{l}\text { Distribution ("4") based on } \\
\text { algorithm, } \mathrm{N}_{\mathrm{I}}=1\end{array}$ & 0.00417 & 2.45 \\
$\begin{array}{l}\text { Distribution ("11") based on } \\
\text { algorithm, } \mathrm{N}_{\mathrm{I}}=1\end{array}$ & 0.0535 & 2.36 \\
$\begin{array}{l}\text { Distribution ("4") based on } \\
\text { algorithm, } \mathrm{N}_{\mathrm{I}}=2\end{array}$ & 0.0493 & 2.16 \\
$\begin{array}{l}\text { Distribution ("11") based on } \\
\text { algorithm, } \mathrm{N}_{\mathrm{I}}=2\end{array}$ & 0.0527 & 2.31 \\
\hline
\end{tabular}

For further elaboration with algorithms, the analysis can focus on creating of favorable conditions under which the inclusions are growing by diffusion coalescence and even to their floating if the conditions are favorable $[9,10]$. However, as there is a limitation here with only one input data - oxygen content - i.e., ignorance of the hydrodynamic regime in ladle steel processing, the only estimate that can be mathematically given is the maximum diameters of inclusions in the first size class. 


\section{Conclusions}

Based on the relations that apply to all distributions of oxide non-metallic inclusions analyzed in this paper and the observed regularities that the distributions obey, it is possible, with certain limitations, to lay the foundations of the algorithm for forming the distribution by size of deoxidation products. When it comes to limitations, in the first place are the type of deoxidant and the method of deoxidation, then the mode of steel ladle treatment and the method of casting, i.e., all these parameters need to be defined for the algorithm of complete quantification of nonmetallic inclusions in extra pure steels. This algorithm is limited to aluminum deoxidized continuously cast steel, for which the hydrodynamic regime of ladle processing is unknown, as well as the oxygen concentration at the time of pouring. Therefore, following the established relations, a possible model algorithm can be given to describe the formation of the distribution of deoxidation products by size when metallographic control is difficult or not feasible by routine procedures, based on mapping the distribution for higher oxygen contents determined by metallographic counting techniques and graphical reconstruction.

\section{Acknowledgement}

The authors wish to acknowledge the financial support from the Ministry of Education, Science and Technological Development of the Republic of Serbia [Grant No 451-03-9/2021-14/200026].

\section{References}

[1] L. Zhang, Q. Ren, H. Duan, Y. Ren, W. Chen, G. Cheng: Miner Process Extr Metall, 129 (2020) 184-206.

[2] D. You, S.K. Michelic, P. Presoly, J. Liu, C. Bernhard: Metals, 7 (2017) 460.

[3] H.V. Atkinson, G. Shi: Prog Mater Sci, 48 (2003) 457-520.

[4] M.D. Mihailović, The use of graphical method for stereological reconstruction of the total amount of non-metallic inclusions in steel, Master of Science Thesis, Faculty of Technology and Metallurgy, Belgrade (2000) 106.

[5] R. Kiessling, Non-metallic Inclusions in Steel, Part V, The Institute of Metals, London (1989) 142-165.

[6] G.F. Vander Voort, Inclusion Measurement, Metallography as a Quality Control Tool, ed. J.L. McCall \&P.M. French, Plenum Press, N.Y. (1980).

[7] E. Plockinger, H. Straube, Leitner-Plockinger, Die Edelstahlerzeugung, SpringerVerlag, Wien (1965) 895.

[8] E. E. McElroy, Applied Business Statistics, Holden-Day, Inc. San Francisco (1979) 548.

[9] Marija D. Jarakovic, Ljubomir B. Nedeljkovic, Mile B. Durdevic: Pract Metall, 33 (1996) 280-293.

[10] A.V. Karasev, D. Gorkusha, K.V. Grigorovich, P.G. Jönsson: Metals, 11 (2021) 448.

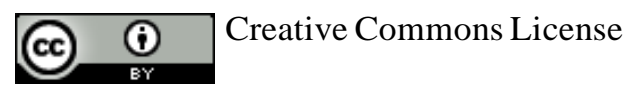

This work is licensed under a Creative Commons Attribution 4.0 International License. 